\title{
Enhancing Sustainable Business by SMEs' Digitalization
}

\author{
Romana Korez Vide \\ University of Maribor
}

\author{
Anica Hunjet \\ University North Varaždin \\ Goran Kozina \\ University North Varaždin
}

In the digital and knowledge society, where SMEs are predominant contributors to economic and social development, SMEs' digitalization is a lever for sustainable business. The purpose of this paper is to argue the importance of SMEs' digitalization for their sustainable business operation and for strengthening their innovation and development potentials. The theoretical part of the paper gives an overview of the topic's backgrounds: sustainable business, the new digital business reality, digital technologies and their functionalities, the state of digital technologies adoption among European micro, small and medium-sized enterprises (SMEs), and the existent governmental and European Union's (EU) support to SMEs' digitalization. In the empirical analysis, we explore business digitalization in the European Union, focusing on Slovenia and Croatia. We found that both Slovenia and Croatia are on a promising path towards SMEs' digitalization; however, they still need to diminish some gaps. We propose some requisite policy responses.

Keywords: sustainable business, SMEs, innovation, digitalisation, Slovenia, Croatia

\section{INTRODUCTION}

Increased digitalization opens up many possible pathways to influence an enterprise's operations and performance (Hanelt et al., 2017). Digitalization, promoted by the use of diverse digital technologies (IT), enables the introduction of changes in business models (Parida, Sjödin \& Reim, 2019). These, in turn, lead to innovations in value creation, allowing the transition to sustainable business models that bring economic, social, and environmental benefits (Lüdeke-Freund \& Dembek, 2017). Implementing sustainable business models encourages sustainable consumption and production, transforming industries and the whole economic system (Bocken, 2019). The adoption of digital technologies enables the widespread use of innovative business models and represents a lever for sustainable business (Hildebrandt et al., 2018).

The outbreak of the COVID-19 pandemic has caused a worldwide socio-economic crisis on an unpredictable scale and triggered the importance of innovative and sustainable operations. Enterprises search for solutions to recover and become more resilient to new, similar shocks in the future, which will probably emerge (see Delivorias \& Scholz, 2020). Resilience enables seizing new or revealed opportunities for systemic improvements after the crises caused by unavoidable disruptions of modern interconnected 
socio-economic systems (Hynes et al., 2020) and paves the path for sustainable business orientation. Quarantines and lockdowns during the COVID-19 pandemic forced enterprises to accelerate digital transformation and implement digital innovations into their business operation. They started to recognize that they could withstand pandemics and maintain agility by using digital technologies that decreased dependence on location and market forces (KPMG International, 2021).

Micro, small and medium-sized enterprises (SMEs) represent most businesses worldwide and essentially contribute to new jobs and global socio-economic development. In the EU-27 non-financial business sector (NFBS), around 21 million SMEs were active in the EU-27 in 2020, accounting for 99.8\% of all enterprises (European Commission, 2021). 93\% of these SMEs were micro-enterprises. In 2020 EU27 SMEs created $53 \%$ of the total value-added and $65 \%$ of the total employment of EU NFBS (European Commission, 2021). Evidence shows that SMEs have been particularly hard hit with the COVID-19 pandemic (see Belitski et al., 2021). 70-80\% of SMEs in OECD countries experienced between 30 to 50\% drop in revenues/sales, and the share of SMEs employment in the sectors most affected by the crisis, was $75 \%$ on average in OECD economies (OECD 2020, 2021). European SMEs had difficulties in importing and exporting materials, goods, or services. They were operating at a loss, faced more than usual late payments, had difficulties sourcing alternative suppliers, paid more than standard prices for materials, goods, or services, and lost their revenues (European Commission, 2021). The SMEs disruptions caused by the COVID-19 pandemic varied widely across SMEs sizes and the Member States.

Many SMEs did not start a digital transition in the pre-COVID-19 times. However, the OECD study (OECD, 2021) shows that since the start of the COVID-19 pandemic, up to 70\% of SMEs are making more digital technologies, although substantial differences exist between SMEs of various sizes, between industrial sectors, and between countries. By digitalization, SMEs improve their operational efficiency (doing things better), deploy predictive actions for operations (doing better things), and produce new goods or provide new services for differentiated customer experience (doing new things) (IBM, 2021).

We structured this paper as follows: sustainable business and digital business reality are introduced in the second and third sections, respectively, the fourth Section discusses available digital technologies and key advantages and challenges of SMEs' digitalization, in the fifth Section, we analyze the adoption of digital technologies in the EU, focusing on Slovenia and Croatia, the six Section presents EU's support to SMEs' digitalization, and in the seven Section we draw a conclusion and implications for policymakers.

\section{SUSTAINABLE BUSINESS}

Sustainable business performance is related to the WCED (1987) concept of sustainable development and Elkington's (1997) concept of a triple bottom line. The first concept stresses the importance of considering the present and the future in meeting the needs. However, the triple bottom line discusses the economic, social, and environmental aspects as a requisite whole on the path towards sustainable organization operations. All three aspects need to be considered equally (Cato, 2009). Economic, social, and environmental factors of development are increasingly intertwined and interdependent. Economic effects cannot be sustainable if they do not benefit society and harm the natural environment.

Sustainable business can be broken down into nine principles (Epstein \& Rejc Buhovac, 2014): ethics (establishment, promotion and maintenance of ethical standards in business with all stakeholders), management (business owners manage their resources diligently and efficiently at the same time focusing on the interests of all stakeholders), transparency (timely disclosure of information on products, services and activities), business relationships (fair trade practices with suppliers and other partners), business success and performance (satisfaction of owners regarding enterprise's operations in terms of profitability), community involvement (promoting business-to-community relations), the value of products / services (respecting the needs and wishes of customers and ensuring the highest product / service quality), employees (practices of dealing with people at work that promote personal and professional development employees), and environmental protection (efforts to protect and restore the environment). 


\section{DIGITAL BUSINESS REALITY}

Increased digitalization of customer service, shift to e-commerce, greater use of self-service, contactless delivery options, outsourced information technology (IT), use of online platforms, remote work arrangements, and increased focus on safety, cleanliness, and health are critical characteristics of the COVID-19 business reality. Enterprises are striving to attain the capability to connect digitally with customers, suppliers, and employees to compete in these new economic and social circumstances. It is requisite for them to address the main challenges related to customer orientation, digital acceleration, more reliable and responsive supply chain operations, new ways of working, and a flexible workforce ecosystem (KPMG, 2021). Enterprises must create customer-centric business models based on selling and engaging through integrated digital channels and offering relevant, personalized, and differentiated customer experiences. They should use data analytics to formulate customer strategies and tactics across marketing and sales to understand changing customer needs and preferences. They should rapidly build in the digital technology infrastructure to connect various enterprises' departments and functions. Based on digital connectivity, supply chain and operations should become more reliable and responsive to ensure continued access to products, materials, people, and services. Enterprises should embrace strategic digital reskilling initiatives to quickly become agile, scaling up or down, entering new markets, and leaving old ones.

\section{AVAILABLE DIGITAL TECHNOLOGIES}

SMEs can use numerous basic and advanced digital technologies or combinations for various purposes (OECD, 2021).

Enterprise resource planning (ERP) systems are software-based tools for managing and integrating internal and external information flows. ERP systems enhance companies' back-office business functions efficiency and strategic planning.

Radio Frequency Identification (RFID) technologies enhance companies' efficiency in production and logistics. Enterprises use them to monitor and control production, supply chain, and inventories.

Customer Relationship Management (CRM) and supply chain management (SCM) software tools enhance companies' front-office integration and supply chain operations. CRM and SCM software help manage a company's interactions with its customers and suppliers.

Cloud computing (CC) helps enhance companies' information technology (IT) systems and capacities. $\mathrm{CC}$ offers access to extra processing power or storage capacity, as well as databases and software, in quantities that suit and follow companies' needs.

Big data (BD) analytics refers to techniques, technologies, and software tools for analyzing large amounts of data generated by electronic activities and digital communications. It could find a broad range of applications within a company, supporting it in decision making and strategic planning, administration, production, logistics, marketing, and sale.

Social media (SM) help increase companies' customer base, business visibility, and outreach. They are used for external interactions, including developing companies' images and marketing products and obtaining or responding to customers' opinions, reviews, and questions. Additionally, enterprises use them to cooperate with business partners and to attract new employees.

E-commerce refers to the sale or purchase of goods or services conducted over computers by specific software for receiving or placing orders. It involves any possible pairing of consumers (B2C, C2B), businesses (B2B), or governments (B2G).

There exist various types of online platforms. The first type is being used for marketing, advertising, branding, customer services, and external communication. Online advertising on web browsers and social media platforms (e.g., Google, Facebook, Twitter) and online marketplace platforms (e.g., Alibaba, Amazon) is prevalent. The second type of these platforms - aggregators -, enable service providers to reach their potential customers more effectively. Due to the network effects, these platforms make matchmaking in the existing market more efficient. Several examples of these platforms are in the hospitality and entertainment industries (e.g., Uber Eats, booking.com, Netflix, Youtube, mobile games on Apple Store). 
The third type of platform - market disruptors -, creates new markets by bringing in new service providers and increasing competition in the same industry (e.g., Airbnb, B\&Bs). The fourth type offers more straightforward access to financial institutions and finance from non-traditional sources (for example, German's Campeon, peer-to-peer lending, and crowdfunding (e.g., Kickstarter, Funding Circle). Financing solutions have also started to offer some large online marketplaces platforms, such as Amazon and Alibaba. The fifth type of online platform supports e-payments by credit cards or other online payment services (e.g., PayPal). The sixth type supports communication, remote working, teleconferencing, and paperless business operations. Enterprises can also use online digital platforms for various communication needs since they offer an attractive networking environment for numerous users (Whatsapp, Skype, Viber, Zoom, Google Meet, MS Teams). The seventh type of online platform is helpful for research and innovation (e.g., digital applications marketplaces or "App stores" and "Play stores"). The openness of digital platforms allows access to the Application Programming Interface (APIs), providing an environment in which innovative products can be developed (e.g., on GitHub can be developed new business applications, website functionalities, and games).

The Internet of Things (IoT) is a network of a wide range of interrelated devices embedded with sensors, actuators, and other necessary electronics that allow them to collect and exchange data over a network via the Internet (Trend Micro, 2019). IoT can't function without artificial intelligence (AI), which analyses and makes sense of these data with minimum human intervention. The enhanced capability of sensors and advances in data processing, such as computer vision, can provide predictions. The main business applications of AI relate to automation, image/face recognition, natural language processing, data analytics, and decision making.

Blockchain is a database that is replicated over a peer-to-peer network. It is often referred to as digital ledger technology (DLT). It can be used to store any type of information (and so of transactions and value) in an unalterable public record distributed in the network. The blockchain industry is developing rapidly in many sectors beyond financial services. Several blockchain solutions have been developed for multiple sectors, such as healthcare, environment, cybersecurity, supply chain management, international trade, digital identity, creative industry, voting, and human resources management. Many solutions are in their experimental phase.

\section{SMES’ DIGITALIZATION}

\section{Adoption of Digital Technologies}

Digital uptake is related to value creation within the firm and the sector in which it operates (OECD, 2021). Recent worldwide business surveys (see OECD, 2021 and European Commission, 2021) found a rapid imposition of remote working and digital sales channels among SMEs. One-third of EU-27 SMEs had adopted or were planning to adopt elementary digital technologies but not the advanced ones. A quarter of EU-27 SMEs had already introduced advanced digital technologies or planned to do so (European Commission, 2021). The need to digitalize and to use advanced digital tools increased significantly with the size of SMEs. Micro enterprises continued to lag in the digital transformation, dragged back by a lack of internal resources and awareness. There exist substantial cross-industry differences in the usage of digital technologies. Concerning the types of digitalized activities, SMEs digitalized administration, sales, and marketing functions first (OECD, 2021). They increased online interactions with governments, business partners, and customers. In knowledge-intensive sectors, enterprises use all types of digital technologies. These sectors almost fully completed some aspects of the digital transformation, while diffusion rates of digital technologies in other sectors are much lower. Numerous SMEs digitalize their business functions by outsourcing digital solutions due to weak internal resources and capabilities.

\section{Key Advantages}

Digitalization enhances SMEs' sustainable business by allowing them to overcome the size-related barriers and achieving numerous advantages: lowering the transactional costs, reducing investment in ICT equipment, delivering and sourcing efficiently, improving productivity, raising integration and interaction, 
creating economies of scale, sharing knowledge, spurring innovation, supporting internationalization, managing transactions at a distance, reducing information asymmetries, facilitating access to financial services, undertaking greener practices and increasing international competitiveness (Bergamaschi et al. (2020); Kutnjak et al. (2019); Cenamor, Parida, \& Wincent (2019); Savastano, Amendola, \& D’Ascenzo (2018); Wittkop, Zulauf, \& Wagner (2018); Costa et al. (2020); cited upon OECD, 2021 and ILO, 2021). More sophisticated digital technologies, such as AI and IoT solutions, can completely alter the SMEs' business models and practices, with numerous positive effects alongside various business functions (Duobao (2019), Agrawal, Gans, and Goldfarb (2018); cited upon OECD, 2021). Overall, SMEs' digitalization supports the changes in existent business models since it supports innovations and sustainable business performance.

\section{Key Challenges}

Despite the clear benefits, digitalization poses several challenges to SMEs. Some of them are very basic, like a lack of critical digital infrastructures, such as fast internet connection, and a lack of required mindset and digital skills (Andrews, Nicoletti, \& Timiliotis (2018), Gal et al. (2019); cited upon OECD, 2021 and European Commission, 2020). The others are related to a lack of awareness and knowledge about the availability, advantages, and effective integration of digital technologies with business models and processes (European Commission, 2020); (Waldman-Brown (2020), Peillon \& Dubruc (2019), Kilimis et al. (2019); cited upon OECD, 2021). SMEs managers are uncertain about the benefits and risks and face mistrust in these technologies. For example, dependency on online platforms can expose SMEs to lock-in effects and unforeseen operational risks, such as sudden changes to platforms' policies and server outages (Mims (2021), Porter (2020), The Economist (2021); cited upon OECD, 2021). In addition, online platforms may not allow user businesses direct access to their customer data, limiting the businesses' understanding of their customer pool (Wiener-Bronner (2020); cited upon OECD). Additionally, different online platform fees may erode SMEs' profitability and deteriorate their competitive position compared to larger businesses with greater bargaining power that can negotiate for lower fees (Dua et al., 2020; cited upon OECD, 2021). As SMEs go digital, their degree of exposure to online attacks is likely to increase dramatically. If being affected, the costs can be disproportionate and can spread deeply into SMEs' supply chains.

\section{THE DIGITAL ECONOMY AND SOCIETY INDEX SCORES OF THE EU MEMBER STATES}

The Digital Economy and Society Index (DESI) tracks the evolution of EU Members States digital performance across dimensions of connectivity, human capital, use of the internet, integration of digital technology, and digital public services, based on their various normalized values in the composite index (European Commission, 2021d). Therefore, SMEs' digitalization is a part of it.

According to DESI, Finland, Sweden, and Denmark were the most digitalized economies and societies in the EU in 2020, Slovenia and Croatia, however, were placed in $16^{\text {th }}$ and $20^{\text {st }}$ place, respectively (see Figure 1). 


\section{FIGURE 1 \\ DIGITAL ECONOMY AND SOCIAL INDEX FOR EU-28 IN 2020}

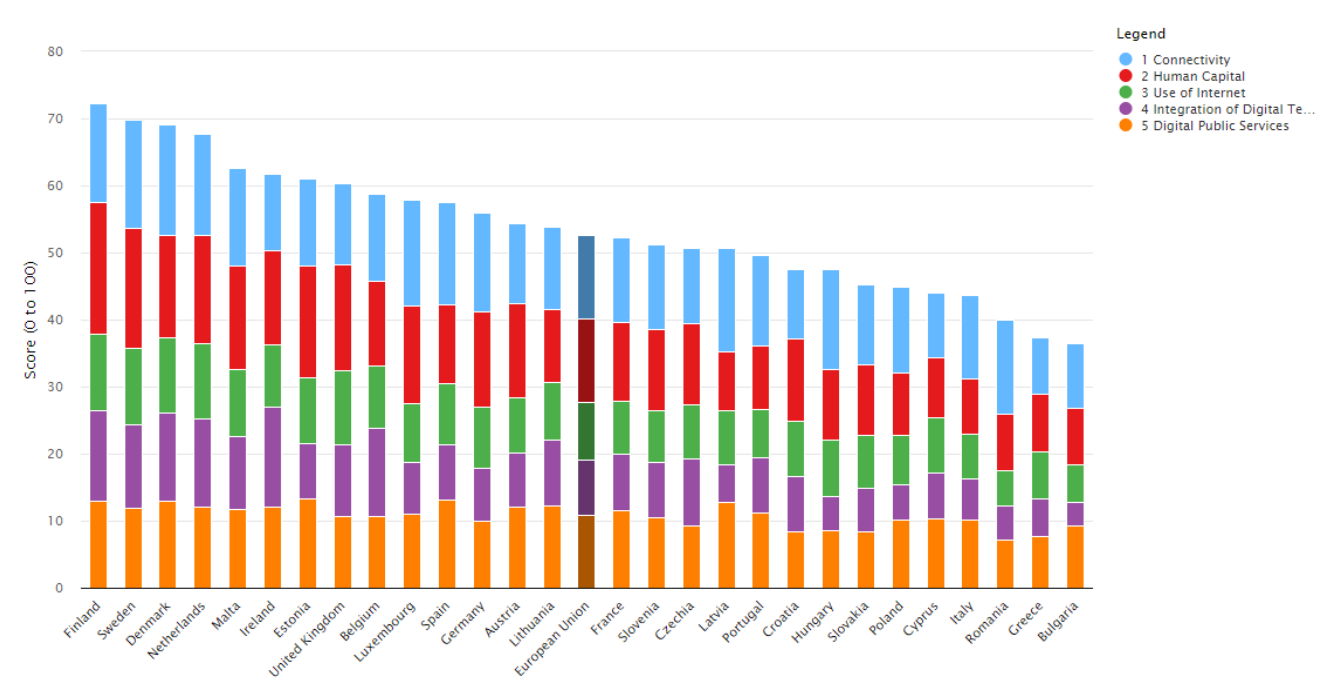

Source: European Commission, 2021d.

The most relevant DESI sub-indicator of SMEs' digitalization is "business digitalization." It is calculated as the weighted average of the normalized values of indicators on Electronic Information Sharing (16.7\%), Social media (16.7\%), Big data (33.3\%), and Cloud Computing (33.3\%). Electronic Information Sharing is measured by the share of all enterprises that have in use an ERP software package, Big Data, however, by the share of all enterprises analyzing big data from any data source, Social Media by the share of all enterprises using two or more social networks, enterprise's blog or microblog, multimedia content sharing websites and wiki-based knowledge sharing tools, and Cloud Computing by the share of all enterprises, purchasing at least one of the particular cloud computing services (European Commission, 2021c). Sub-indicator "business digitalization" considers all businesses, not only SMEs. Figure 2 shows that the highest business digitalization was achieved in Finland, Netherlands, and Belgium in 2020, whereas Slovenia and Croatia were $17^{\text {th }}$ and $15^{\text {th }}$, respectively.

\section{FIGURE 2 \\ BUSINESS DIGITALIZATION OF EU28 IN 2020}

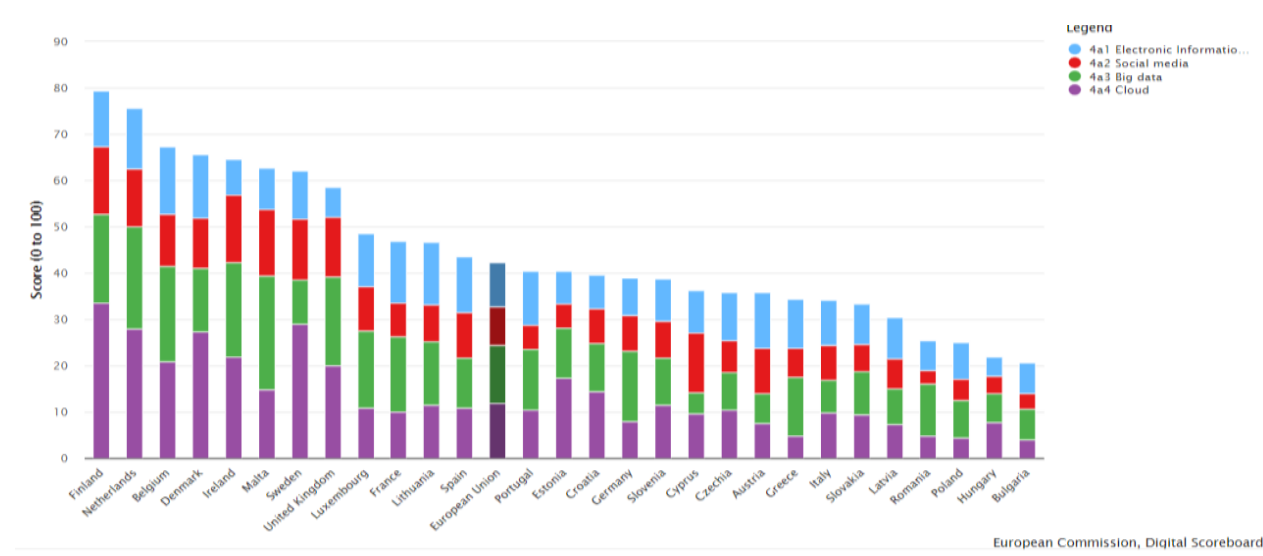

Source: European Commission, 2021d.

Slovenia achieved the highest score in Cloud Computing (11.4), Big Data (10.3), Electronic Information Sharing (9.1), and Social Media (7.95) in 2020 (Figure 3). 
FIGURE 3

\section{BUSINESS DIGITALIZATION OF SLOVENIA IN 2020}

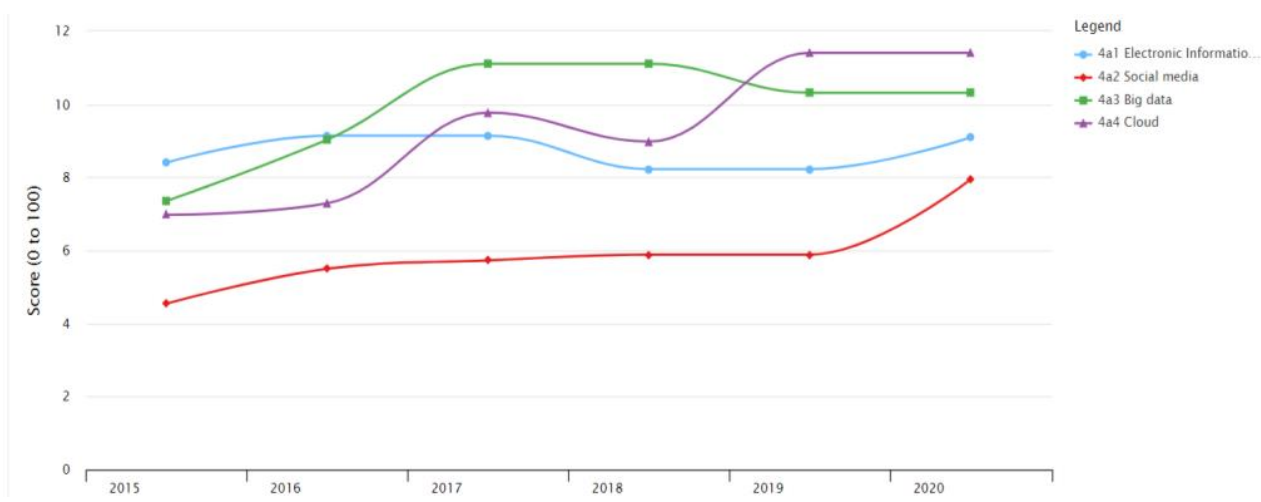

Source: European Commission, 2021d.

Croatia achieved, however, the highest score on Cloud Computing (14.5), followed by Big Data (10.4), Social Media (7.46), and Electronic Information Sharing (7.21) (Figure 4).

FIGURE 4

BUSINESS DIGITALIZATION OF CROATIA IN 2020

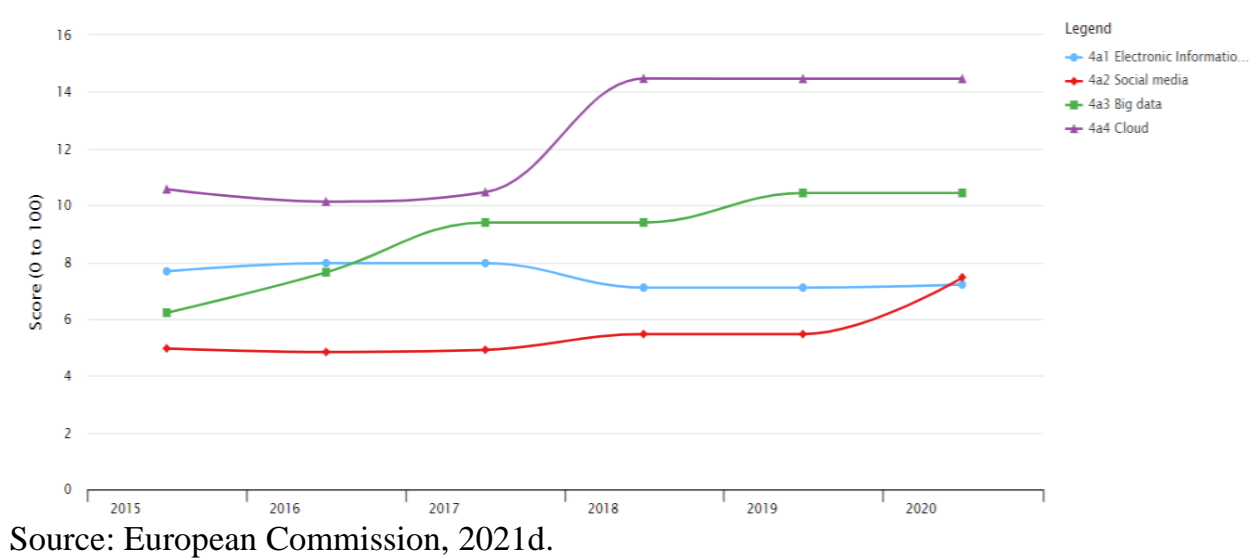

Although both countries have made progress in some fields of business digitalization, there is still much space for improvement.

\section{POLICY SUPPORT TO SMES' DIGITALIZATION}

Considering the state of digital technologies' adoption among SMEs, several advantages and challenges of their usage, the awareness making, and support to SMEs digitalization should be strengthened in the contemporary dynamic and uncertain global economy.

Policymakers have a crucial role in helping SMEs to adapt their business processes to the contemporary digitalized world. Policy interventions span across a broad range of areas, including awareness campaigns, training, and technical assistance, access to finance, support for the development of SME-tailored digital solutions, establishing data centres, experimentation platforms and networking programs, regulatory reforms, e-government and one-stop-shops, and investment in ICT infrastructure. 


\section{Governmental Support}

Governments encourage the digitalization of SMEs with various policy approaches. They introduce new policies or adjust existing ones to accelerate SMEs' availability and use of digital tools. Policy interventions specify different ministries and agencies in charge. Fundamental cross-cutting actions include raising the awareness of the digital technologies' benefits, tailored technical advisory support services combined with financial support, and supporting skills development through mentoring, training, education (European Commission, 2021). The same governmental interventions were implemented during the COVID-19 pandemic (Cirera et al., 2021; cited upon OECD 2020, 2021; ILO, 2021). Some governments also adjusted regulatory frameworks and legislation to support the deployment of new working arrangements and business models based on digitalization (OECD, 2021). However, the extent to which specific measures would be helpful to SMEs varied across countries and enterprises's sizes.

\section{European Union's and OECD's Support}

The European Union (EU) supports the digital transformation of SMEs with the following policies (European Council, 2021): facilitation of digital single market through digital sovereignty, strengthening and modernising the rules for digital services on online platforms, building the data economy by ensuring data sharing and data reuse across sectors and borders as a basis for new digital innovations, adapting taxation systems to the digital age, promoting innovations in AI research and deploying and encouraging the ethical and human-centric approach to this technology, supporting enabling technologies, like for instance cloud computing, high-performance computing, and quantum technologies, assuring fast and ubiquitous digital connectivity across the EU, enhancing cybersecurity to ensure greater trust in digital technology, enabling secure public electronic identification (e-ID), supporting the improvement of digital education and upskilling of the workforce, improving access to justice and increasing the effectiveness of court proceedings. Within the EU Multiannual Financial Framework 2021-2027, these policies will be supported by the Digital European Programme (DEP) that will provide funding in five key capacity areas (European Commission, 2021a): super-computing, artificial intelligence, cybersecurity, advancing digital skills, and ensuring a wide use of digital technologies. The DEP funds will be complemented with other EU programs, such as the Horizon, the Connecting Europe Facility, the Recovery and Resilience Facility, and the Structural Funds. DEP envisaged the establishment of the European Digital Innovation Hubs (EDIH) network, based on the already existing network of Digital Innovation Hubs (DIH). DIH started to develop across the EU five years ago as one-stop shops to support the framework conditions for the digital industrial revolution with piloting, testing, and experimenting with digital innovations (European Commission, 2021b). EDIHs are planned to have both local and European functions. EU funding will be made available for hubs that their Member States already support. The DEP intends to increase the capacities of the selected hubs to cover activities with European added value, based on networking the DIHs and promoting the transfer of expertise. EDIHs will introduce new approaches and processes, aided by advanced technologies such as artificial intelligence, super-computing (HPC), and cyber security. There are currently more than 600 DIHs in various evolutionary stages (in preparation, fully operational, and potential), technologies, providing services all over the EU27 member states, and more than 80 DIHs in eleven non-EU members states (European Commission, 2021c). More than 330 DIHs are nominated for European DIH in the EU and additional 6 DIHs in Norway. In Slovenia, there are $12 \mathrm{DIHs}$ in various evolutionary stages and three candidate DIHs for European DIH. In Croatia, however, there are 17 DIHs and five candidate DIHs for European DIH. European Institute of Innovation and Technology (EINT) delivers digital innovations to the market by mobilizing a pan-European ecosystem of top European corporations, SMEs, start-ups, universities, and research institutes. It will contribute to the network of EDIHs through its project Manufacturing Industry Digital Innovation Hubs (MIDIH) (MIDIH, 2021). Several other EU actions and mechanisms support SMEs' digitalization, such as the European Alliance for Apprenticeships, Digital Skills and Jobs Coalition, and the launch of Digital Education Action Plan 20212027.

The OECD supports digitalization by the D4SMEs Global Initiative. D4SMEs aims to promote knowledge sharing and learning among governments, large corporations, industry experts, and SMEs on 
crucial thematic areas relevant to SME digitalization. Knowledge sharing and learning include enabling framework conditions, firm-level triggers, new digital technologies and applications, and digitally-driven transformations in supply chains and business models (see OECD, n.d.)

\section{CONCLUSION AND IMPLICATIONS FOR POLICYMAKERS}

The COVID-19 crisis demands enterprises' innovations and sustainable business operations. This finding is significant for SMEs, as economies' driving forces. SMEs' digitalization supports innovation and sustainable business; therefore, the COVID-19 crisis accelerates SMEs' digitalization. Enterprises move their operations online and implement digital tools to remain in business and overcome disruptions in supply chains. Digital practices learned during the COVID-19 pandemic crisis will enable SMEs to achieve greater resilience for possible future disruptions. The adoption of digital technologies facilitates sustainable development. At the systemic level, the resilience of an economic system supports its long-term sustainability.

Overcoming digital gaps, which could allow SMEs to fully embrace the digital transformation benefits, SMEs cannot meet alone. Policymakers have a substantial role to play. Due to the socio-economic importance of SMEs, a failure to support them in the process of post-COVID-19 recovery through digitalization could have adverse long-term effects on economies. It is pertinent to support SMEs in building data culture, from collection to management, protection, and analysis. Governments should raise awareness among SMEs about the benefits of digital tools, particularly more sophisticated ones (such as AI and blockchain), where the digital gap among SMEs is the largest. They should further support reskilling of SMEs managers and workers and ensure a participatory approach for redesigning work processes and training to implement new digital solutions. With concrete business cases, SMEs should also receive more evidence on the return on investment of new digital technologies and sectoral impact. Governments should also inform SMEs about the existence of international platforms, supporting a digital transition, and the possibilities of SMEs' knowledge sharing and mutual learning.

Further research could address innovations in digital business solutions, particularly in artificial intelligence and blockchain applications, and their positive impacts on SMEs' activities and processes. It would also be reasonable to follow the contributions of the EU's Digital Innovation Hubs Network to European SMEs' digital transformation and the innovations in the approaches and technologies to prevent and mitigate cybersecurity risks. Since digitalization supports sustainable business performance, further studies could also address digitalization's influences on each of the three sustainability dimensions.

\section{REFERENCES}

Belitski, M., Guenther, C., Kritikos, A.S., \& Thurik, R. (2021). Economic Effects of the COVID-19 Pandemic on Entrepreneurship and Small Businesses. IZA Discussion Paper No. 14630. Retrieved from https://ftp.iza.org/dp14630.pdf

Bocken, N. (2019). Sustainable consumption through new business models: The role of sustainable entrepreneurship. In A. Lindgreen, F. Maon, \& C. Vallaster (Eds.), Sustainable Entrepreneurship: Discovering, Creating and Seizing Opportunities for Blended Value Generation. London and New York: Routledge.

Cato, M. (2009). Green Economics, and introduction to theory, policy, and practice. London: Earthscan.

Delivorias, A., \& Scholz, N. (2020). The economic impact of epidemics and pandemics. European Parliament Briefing. Retrieved from https://www.europarl.europa.eu/RegData/etudes/ BRIE/2020/646195/EPRS_BRI(2020)646195_EN.pdf

Elkington, J. (1997). Cannibals with Forks: The Triple Bottom Line of $21^{\text {st }}$-century Business. Hoboken, New Jersey: John Wiley \& Sons Ltd.

Epstein, M., \& Rejc Buhovac, A. (2014). Making sustainability work: Best practices in managing and measuring corporate social, environmental, and economic impacts ( $2^{\text {nd }}$ Ed.). San Francisco: Berrett-Koehler Publishers. 
European Commission. (2021a). Annual Report on European SMEs 2020/2021. Digitalisation of SMEs. SME Performance Review 2020/2021. Retrieved from https://op.europa.eu/en/publicationdetail//publication/4b9b0f42-dade-11eb-895a-01aa75ed71a1/language-en/format-PDF/sourcesearch

European Commission. (2021b). Shaping Europe's digital future. The digital Europe Programme.

Retrieved from https://digital-strategy.ec.europa.eu/en/activities/digital-programme

European Commission. (2021c). Digital Innovation Hubs Network. Retrieved from https://dihnet.eu/

European Commission. (2021d). Smart Specialisation Platform. Digital Innovation Hubs. Retrieved from https://s3platform.jrc.ec.europa.eu/digital-innovation-hubs

European Commission. (2021e). Digital Economy and Society Index. Retrieved from https://digital-agenda-data.eu/

Hanelt, A., Busse, S., \& Kolbe, L.M. (2017). Driving business transformation toward sustainability: Exploring the impact of supporting IS on the performance contribution of eco-innovations. Information systems Journal, 27(4), 463-502. http://doi.org/10.1111/isj.12130

Hildebrandt, B., Hanelt, A., \& Firk, S. (2018). Sharing Yet Caring: Mitigating Moral Hazard in Access-Based Consumption through IS-Enabled Value Co-Capturing with Consumers. Business \& Information Systems Engineering, 60(3). https://doi.org/10.1007/s12599018-0532-6

Hynes, W., Trump, B., Love, P., \& Linkov, I. (2020). Bouncing forward: A resilience approach to dealing with COVID-19 and future systemic shocks. Environment Systems and Decisions, 40(2), 174184.

IBM. (2021). Digital Transformation Assessment COVID-19: A catalyst for change. Retrieved from https://www.ibm.com/downloads/cas/MPQGMEN9

ILO. (2021). Small goes digital - How digitalization can bring about productive growth for micro and small enterprises. Retrieved from https://www.ilo.org/wcmsp5/groups/public/---ed_emp/---emp_ent/--ifp_seed/documents/publication/wcms_808632.pdf

KPMG International. (2021). Going Digital, Faster. Global Survey into the impact of COVID-19 on digital transformation. Retrieved from

https://home.kpmg/xx/en/home/services/advisory/management-consulting/kpmg-connectedenterprise/going-digital-faster.html

Lüdeke-Freund, F., \& Dembek, K. (2017). Sustainable business model research and practice: Emerging field or passing fancy? Journal of Cleaner Production, 168, 1668-1678.

https://doi.org/10.1016/J.JCLEPRO.2017.08.093

OECD. (2020). Coronavirus (COVID-19): SME policy responses. OECD Policy Responses to Coronavirus (COVID-19). Retrieved from http://www.oecd.org/coronavirus/policyresponses/coronavirus-covid-19-sme-policy-responses-04440101/

OECD. (2021). The Digital Transformation of SMEs. Retrieved from https://www.oecd.org/publications/the-digital-transformation-of-smes-bdb9256a-en.htm

OECD. (n.d.). OECD Digital for SMEs Global Initiative. Retrieved from https://www.oecd.org/goingdigital/sme/

Parida, V., Sjödin, D., \& Reim, W. (2019). Reviewing Literature on Digitalization, Business Model Innovation, and Sustainable Industry: Past Achievements and Future Promises. Sustainability, 11(2), 391. https://doi.org/10.3390/su11020391

Trend Micro. (2021). Internet of Things. Retrieved from https://www.trendmicro.com/vinfo/ph/security/definition/internet-of-things

WCED (World Commission on Environment and Development). (1987). Report of the World Commission on Environment and Development: Our Common Future. Retrieved from http://www.un-documents.net/our-common-future.pdf 